Ärztliche Erfahrung beschränkt sich nicht auf medizinisches Fachwissen.

\title{
Hat Maxi das Zeug zum Begleithund?
}

Neulich kam Frau S. zu uns in die Praxis. Sie lebt schon lange mit einer Reihe von Einschränkungen. Unter anderem ist sie gehbehindert und schwerhörig. „Herr Doktor, ich brauche einen Begleithund!“, eröffnete sie mir nun. „Ihr Kollege aus der Uniklinik meint das auch. Und die Krankenkasse sagt, Sie müssten mir den Hund verschreiben! " Wohlwollend, aber ratlos fragte ich: „Ist das so etwas wie ein Blindenhund?" „Nein, ich kann ja gut sehen!“

Ich erkundigte mich, was so ein Hund denn können müsse. „Das weiß ich nicht", entgegnete die Patientin, „aber mein Hund ist bisher ganz in Ordnung." Nun war ich erst recht verwirrt. "Sie haben den Hund schon? Ist der denn als Begleithund ausgebildet?" Die Patientin verneinte, woraufhin ich fragte, ob der Hund das noch lernen könnte. "Ach, das glaube ich nicht. Maxi ist ja schon älter“, erklärte die Dame. Zudem sei er als Zwergpinscher nicht besonders groß. „Aber er ist ein guter Begleiter!“, war sich die Patientin sicher.

Nach einer ratlosen Pause ahnte sie, dass ihr Plan nicht aufgehen würde. „Ach wie schade!“, rief sie. „Wissen Sie, der neue Vermieter will Hunde im Haus verbieten. Und ich will doch den Maxi nicht hergeben“, berichtete sie. In dieser misslichen Lage hätte sie die Bescheinigung, dass Maxi ihr Begleithund ist, gut brauchen können. „Vielleicht könnte Ihre Frau da was machen?", fragte sie noch. „Die ist doch Hausärztin!“

Doch auch der Frau Doktor fiel für das durchaus berechtigte Anliegen keine medizinische Lösung ein. So blieb uns nur, die Patientin auf den Mieterverein aufmerksam zu machen.

Dres. Gisela und Werner Gieselmann, Heiligenhaus

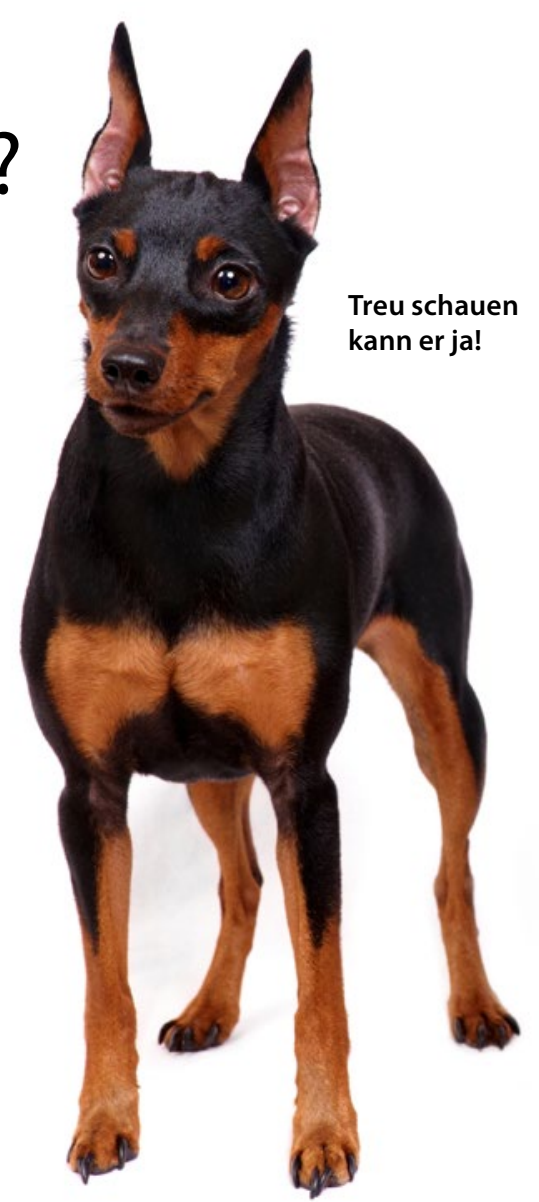

Treu schauen kann er ja!

\section{Durchsuchung machen wir hier im Dorf}

_ Mit verschränkten Armen und versteinerter Miene saß ein älterer Herr im Sprechzimmer, als ich hereinkam. Auf meine Begrüßung hin kam nur ein kurzes, grummeliges Grunzen. Ich beschloss, zunächst nicht auf diese Situation einzugehen und begann stattdessen, den Bericht der Nephrologin mit dem Patienten zu besprechen.
Plötzlich platzte es aus ihm heraus, und er begann, mir seinen Unmut zu erklären. Nie wieder würde er zu dieser Nierenärztin gehen! Bei der ersten "Durchsuchung" sei sie noch ganz freundlich zu ihm gewesen, aber schon bei der zweiten „Durchsuchung“ hätte sie ihre Helferinnen alles machen lassen und sei nur kurz „reingerauscht“. Er wolle zukünftig nicht mehr von Fachärzten in der nahegelegenen Stadt behandelt werden: „Was die machen, können Sie hier im Dorf schon lange.“

Dieses Vertrauen in meine Kunst ehrte mich als Hausärztin, auch wenn es die Untersuchung und Behandlung auch in Zukunft nicht erleichtern wird.

Dr. Claudia Krite-Anthes, Springe 